DOI: http://dx.doi.org/10.18569/tempus.v10i2.1657

\title{
Um Serious Game para Educação Sobre Saúde Bucal em Bebês.
}

\section{A Serious Game for Education about Oral Health in Babies.}

\section{Un Serious Game para la Educación sobre la Salud Oral en Bebés.}

Liliane dos Santos Machado Ana Maria Gondim Valença ${ }^{2}$

Alana Marques de Morais ${ }^{3}$

RESUMO: Os serious games têm se destacado pela adição de aspectos lúdicos ao processo educacional, motivando e auxiliando o aprendizado por meio de jogos. Neste contexto, a inteligência do jogo, composta a partir de modelos de decisão, constitui-se elemento desafiador e motivador do jogador. Para o presente estudo, observou-se que os conceitos básicos relacionados à saúde e higiene bucal predominam nos serious games para Odontologia, e as crianças são o públicoalvo principal destes jogos. A carência na exploração da temática saúde bucal em bebês em jogos foi abordada neste trabalho a partir do desenvolvimento de um serious game. A concepção do jogo "Uma Aventura na Floresta da Dentolândia" permitiu verificar a necessidade de considerar a temática e o público-alvo no processo de desenvolvimento de serious games. A pesquisa realizada também permitiu verificar as amplas possibilidades para uso de serious games aplicados à área de saúde.

Palavras-chave: jogos, serious games, odontologia, odontopediatria, educação

ABSTRACT: The serious games have been highlighted by the addition of playful aspects to the educational process, motivating and assisting learning through games. In this context, the game intelligence, comprised from decision models, consists of challenging and motivating element for

1 Cientista da Computação, docente do Departamento de Informática e pesquisadora junto ao Laboratório de Tecnologias para o Ensino Virtual e Estatística (LabTEVE) da Universidade Federal da Paraíba. liliane@di.ufpb.br

2 Odontóloga e docente do Departamento de Odontologia Clínica e Social da Universidade Federal da Paraíba. anamvalenca@gmail.com

3 Tecnóloga em Sistemas para Internet e Mestre em Modelos de Decisão e Saúde pela Universidade Federal da Paraíba. alanam2@gmail.com 
the player. For the present study, it was observed that basic concepts related to health and oral hygiene predominate in serious games for Dentistry and children are the main target audience of these games. The shortage in exploring games with the theme oral health for infant was the focus of the development of a serious game addressed to this theme. The design of the game "Uma Aventura na Floresta da Dentolândia" (An Adventure in the Toothland Forest) allowed verifying the necessity of consider the theme and the target public in the development process of serious games. The research also allowed verifying a wide range of possibilities for the application of serious games in health.

Keywords: games, serious games, dentistry, pediatric dentistry, education.

RESUMEN: Los serious games se han destacado por la adición de aspectos lúdicos en el proceso educativo, motivando y ayudando el aprendizaje a través de juegos. En este contexto, la inteligencia del juego, compuesta por modelos de decisión, contiene elementos desafiantes y de motivación para el jugador. Para el presente estudio, se observó que los conceptos básicos relacionados con la salud y la higiene bucal predominan en los serious games para odontología y que los bebés son el principal público objetivo de estos juegos. La escasez en explorar el tema de salud bucal de bebés de forma lúdica fue el tema central de este estudio, a partir del desarrollo de un serious game volcado a este tema. La concepción del juego "Uma Aventura na Floresta da Dentolândia" (Una Aventura en el Bosque de la Toothlanden) demostró la necesidad de considerar el tema y el público objetivo en el proceso de desarrollo de los serious games. La investigación también permitió comprobar una amplia gama de posibilidades para la aplicación de los serious games en salud.

Palabras clave: juegos, serious games, odontología, odontología pediátrica, educación.

\section{INTRODUÇÃO}

As mídias digitais interativas alcançam a maioria dos espaços na sociedade contemporânea ao mesmo tempo em que pesquisas provam a eficácia de aplicações computacionais para o aumento da motivação e na consolidação do conhecimento durante o processo de ensino-aprendizagem ${ }^{1}$. Neste contexto, os jogos computacionais se destacam quando comparados a outras mídias, pois possibilitam um equilíbrio entre o desafio e o envolvimento do jogador durante a interação ${ }^{2}$. Especificamente, os serious games têm como característica principal propiciar o aprendizado de aspectos específicos de disciplinas ou treinar habilidades operacionais ${ }^{4}$. Kebritchi e Hirumi ${ }^{1}$ atribuem o êxito dos serious games a uma série de fatores, dentre eles: o uso da ação ao invés da explanação; a criação de uma motivação e satisfação pessoal; a adaptação a vários estilos de aprendizagem e de competências; o reforço das habilidades; e estímulo aos processos decisórios do jogador em ambientes interativos. O primeiro censo da indústria brasileira de jogos, divulgado no ano de 2014 (com dados do ano de 2013), apontou que os serious games correspondiam a quase metade dos jogos desenvolvidos no Brasil (47,8\%), sendo que aqueles voltados especificamente para a saúde correspondiam a apenas $4 \%$ do total dos jogos produzidos naquele ano ${ }^{4}$.

Em crianças de 18 a 60 meses de idade, foi observado que 21,2\% delas apresentavam pelo Tempus, actas de saúde colet, Brasília, 10(2), 167-188, jun, 2016.

ISSN 1982-8829 
menos um dente de leite com experiência de cárie dentária ${ }^{5}$ enquanto, aos 5 anos, este percentual se elevou para $53,5 \%{ }^{6}$. O mais recente inquérito populacional sobre as condições de saúde bucal da população brasileira apontou que tal situação tendia a piorar com o passar da idade, chegando a 56,5\% de crianças de 12 anos com experiência de cárie e, em adolescentes de 15 a 19 anos, 76,1\% ${ }^{6}$. Tais índices mostravam-se agravados por uma higienização bucal inadequada, pelo consumo elevado de carboidratos fermentáveis, pela falta de acompanhamento odontológico e pela falta de orientação adequada de pais e responsáveis. Além disso, no que diz respeito a atitudes maternas frente à cárie dentária envolvendo dentes de leite de seus filhos, 93,5\% das mães relataram que os levariam ao dentista se os dentes estivessem acometidos por cárie dentária, ou seja, procurariam atenção em saúde bucal se seus filhos apresentassem alterações, podendo a criança, neste estágio, sentir de dor e exigir tratamentos mais complexos ${ }^{7}$. Apesar da melhoria nas estratégias brasileiras voltadas à saúde bucal do bebê, ainda se percebe a necessidade de iniciativas e ações sobre a importância dos dentes de leite e de como prevenir a cárie dentária desde uma tenra idade ${ }^{8}$.

No contexto de poucas políticas públicas relacionadas à saúde bucal de bebês, principalmente no âmbito brasileiro e no cenário das mídias digitais, particularmente no uso de serious games voltados a processos educativos, surgiu a motivação para esse trabalho.

Na pesquisa aqui apresentada, lidou-se com a hipótese de uso de serious games no processo de informação quanto às práticas de higienização bucal de bebês. Portanto, se constituem em objetivos deste trabalho: identificar, por meio de pesquisa bibliográfica, as aplicações computacionais desenvolvidas na forma de serious games para Odontologia e suas características; apresentar os processos de planejamento e de desenvolvimento de um serious game, composto por um modelo inteligente de tomada de decisão, voltado ao aprendizado de saúde bucal em bebês. O modelo de decisão, presente na inteligência artificial deste jogo, serviu como um elemento desafiador e motivador no processo de informação e aprendizado do público-alvo.

\section{METODOLOGIA}

O desenvolvimento deste trabalho consistiu em cinco etapas. Na primeira delas foi realizada uma pesquisa exploratória para identificar aplicações computacionais desenvolvidas na forma de serious games para Odontologia, a saber: pesquisa em bases de trabalhos científicos, seleção de jogos comerciais e busca de serious games apresentados em campanhas educativas.

Na primeira etapa, os repositórios de trabalhos científicos pesquisados foram: IEEE Xplore, Science Direct, PubMed.gov Periódicos CAPES, Biblioteca on-line da SBC e Google Acadêmico. Esta fase contemplou a busca em 30 revistas (20 multidisciplinares e 10 computacionais) e 9 anais de congressos específicos de jogos, a partir de 2005. As pesquisas foram realizadas por meio de buscas das seguintes palavras-chave nos repositórios destacados: health computer games, serious games, interactive computer games, computer games in dentistry, serious games in dentistry, jogos sérios, videogames na Odontologia, jogos computacionais na Odontologia, serious games na 
Odontologia e jogos em odontopediatria.

No momento seguinte do levantamento, a estratégia de pesquisa restringiu-se aos sítios na Internet de empresas relacionadas ao desenvolvimento de serious games e pesquisas de jogos em sítios de busca como Google e Bing. Alguns sítios da web reuniam e referenciavam jogos de diversos desenvolvedores. A seguir, estão listados os repositórios e trabalhos pesquisados (links atualizados de 10 de junho de 2015).

Sítio web: http://jogosdedentista.com

Sítio web: http://www.hospitalgames.co.uk/dentist-games

Sítio web: http://oralhealthamerica.org

Sítio web: http://www.dentistgames.biz

Sítio web: http://breakawaygames.com

Sítio web: http://www.colgate.com.br

Sítio web: http://www.colgate.com

Sítio web: http://www.healthgamesresearch.org

Sítio web: http://www.deltadentalnj.com/kidsclub

Sítio web: http://www.mouthhealthykids.org

Sítio web: http://pt.y8.com/games/foamworks_squirt

Sítio web: http://www.surgerysquad.com/surgeries/virtual-dental-filling-composite-amalgam

Sítio web: https://play.google.com

Sítio web: http://iguinho.com.br/escova.html

Ito $(2011)^{9}$

Kolesnikov et al. (2009) ${ }^{10}$

Rodrigues et al. (2014) ${ }^{11}$

Os jogos selecionados na pesquisa foram analisados e avaliados em relação às seguintes características: temática explorada, público-alvo, diferencial, distribuição da ferramenta e tipo de visualização. Nesta análise, foram descartados os jogos que não se enquadravam na modalidade de serious games, ou seja, não se relacionavam ou transmitiam informação específica ao jogador durante a interação.

Nesse sentido, teve início a segunda etapa desse trabalho que se tratou de uma pesquisa do tipo exploratória para a consulta ao público-alvo, a partir do desenvolvimento de uma aplicação teste. O cenário de pesquisa foi a Clínica de Odontopediatria da Universidade Federal da Paraíba e os sujeitos, as mães usuárias desse serviço. Para a investigação foi elaborado um formulário composto por quatro grupos de perguntas: a relação da mãe com o dentista, o perfil socioeconômico, os conhecimentos gerais sobre a temática e a impressão da mãe sobre os jogos testados. O procedimento de coleta de dados ocorreu com o acesso às mães, por meio de uma entrevista no formato de uma enquete estendida, devido ao número de questões. Os dados obtidos nos formulários foram analisados descritivamente, mediante valores absolutos e percentuais. A partir destes resultados se 
definiu qual abordagem era a mais adequada ao serious game proposto.

Os resultados da pesquisa com o público-alvo foram utilizados na concepção do roteiro final (terceira etapa) e no desenvolvimento (quarta etapa) do serious game "Uma Aventura na Floresta da Dentolândia". Na etapa final, o jogo foi avaliado no mesmo local de aplicação dos formulários anteriores, de modo a identificar a aceitação do mesmo, sua efetividade e receber sugestões dos jogadores.

Esta pesquisa foi aprovada pelo Comitê de Ética em Pesquisa com Seres Humanos (CEP) do Hospital Universitário Lauro Wanderley (HULW) na Universidade Federal da Paraíba (UFPB), Protocolo no 167/09 e FR: 285463. A coleta de dados, referente aos testes, foi realizada na Clínica de Odontopediatria e na Clínica Integrada Infantil, pertencentes à Universidade Federal da Paraíba. A pesquisa recebeu financiamento parcial da Coordenação de Aperfeiçoamento de Pessoal de Nível Superior (CAPES) e do Conselho Nacional de Desenvolvimento Científico e tecnológico (CNPq).

\section{RESULTADOS}

\section{a) Análise dos Serious Game em Odontologia}

Na primeira etapa da pesquisa foram identificados 24 serious games relacionados à saúde bucal, tendo sido observado um predomínio de dois grupos de público-alvo: estudantes de Odontologia e crianças. Em geral, os jogos voltados para o público infantil abordavam conceitos relacionados à alimentação e higiene bucal. Outro grupo de jogos estava direcionado aos estudantes e profissionais de Odontologia e se baseavam no realismo com intuito de reforçar o aprendizado ou treinar habilidades. Observou-se também que as ferramentas existentes no mercado e na literatura, considerando o período e as bases analisadas, se limitavam a quatro temas principais: conceitos básicos de saúde bucal, higiene bucal de crianças e adultos, ida ao dentista e treinamento de profissionais.

A partir dos resultados da análise exploratória foi possível notar a ausência de jogos voltados para a educação de mães e cuidadores de bebês. Diferente dos jogos voltados à formação ou capacitação profissional, notou-se que os serious games para o público infantil visavam afetar diretamente a saúde do jogador e não uma terceira pessoa, como é o caso da higiene bucal de bebês.

De modo a conceber um serious game para tal finalidade, uma nova etapa de planejamento foi iniciada com a necessidade de definir e compreender o público-alvo potencial do jogo.

\section{b) Planejamento do Serious Game}

Não há padrões definidos para o planejamento e desenvolvimento de um serious game voltado para Saúde, especificamente para a Odontologia. Entretanto, sabe-se que dois fatores precisam ser definidos primordialmente em qualquer jogo: o público-alvo e o objetivo. Somente com estes dois 
pontos especificados é que se pode avançar para as próximas etapas da concepção de um serious game de cunho educativo: o planejamento pedagógico, a escolha da metodologia, a definição do roteiro e a elaboração dos desafios. Neste sentido, este trabalho definiu as mães como público-alvo e o objetivo de informar e educar esses jogadores sobre conceitos relacionados à saúde bucal de bebês.

Durante o planejamento do serious game "Uma Aventura na Floresta da Dentolândia", as reuniões da equipe multidisciplinar foram fundamentais para a definição de diversos aspectos do jogo, entre eles: os conceitos pedagógicos relevantes dentro da temática e a necessidade de uma análise prévia sobre a opinião do público-alvo. A proposta do produto final - um jogo - não pretendeu substituir a atuação dos profissionais da Saúde no desenvolvimento de ações de educação em saúde, mas ser uma ferramenta extra e com caráter auxiliar no processo de informação ou de ratificação dos conceitos relacionados à saúde bucal de bebês.

Para fins didáticos, a etapa de planejamento deste projeto foi dividida nas seguintes subseções: definição dos conteúdos pedagógicos, aspectos éticos do projeto e planejamento dos testes com o público-alvo. Neste projeto, a definição do conteúdo pedagógico se deu sob a orientação de um especialista da Odontologia, o que permitiu organizar o conteúdo abordado no jogo em oito tópicos:

1. Aspectos relacionados à dieta alimentar;

2. Técnicas de higienização bucal em bebês;

3. Erupção dos dentes decíduos;

4. Fatores de riscos no desenvolvimento da cárie mamária e da cárie infantil;

5. Ida ao dentista: informações da idade adequada da ida do bebê ao dentista e o que esperar das primeiras consultas;

6. Técnicas para ensinar boas condutas de higiene bucal à criança;

7. Doenças que o cuidador pode transmitir ao bebê através da boca;

8. Importância da saúde bucal da mãe e do seu bebê.

O processo de desenvolvimento do serious game percorreu, em linhas gerais, as seguintes etapas: conceituação, definição do Design Bible ${ }^{2}$, prototipagem, implementação e produção dos sons/imagens, testes e finalização do produto. Para o planejamento do jogo, este trabalho utilizou uma metodologia baseada na avaliação da Abordagem de Comunicação do jogo. A Abordagem de Comunicação engloba uma série de elementos importantes na construção do jogo, dentre elas: conceituação artística, tipo de narrativa, roteiro, enredo, ambiente, interatividade, gênero do jogo e jogabilidade. Portanto, estes elementos são importantes tanto nas etapas de conceituação quanto de 
definição do Design Bible, pois definem como o conteúdo pedagógico deve ser apresentado na tela e explorado pelo jogador ${ }^{12}$. A definição desta abordagem seguiu a estratégia de atuação:

- Planejamento, com a equipe multidisciplinar, das Abordagens de Comunicação utilizadas na avaliação;

- Construção de storyboard dos protótipos das Abordagens de Comunicação;

- Reunião com a equipe multidisciplinar e correção do storyboard;

- Desenvolvimento dos protótipos;

- $\quad$ Testes junto ao público-alvo;

- Avaliação dos resultados.

De modo a avaliar qual Abordagem de Comunicação mais se adequava ao público-alvo, foram desenvolvidos dois protótipos de teste com abordagens distintas, de modo que potenciais usuários pudessem testar e opinar sobre os protótipos. Esta informação foi relevante na construção do serious game porque influenciou diretamente na elaboração do roteiro, dos desafios, na confecção das mensagens, na construção das telas e nas formas de interação disponibilizadas ao jogador.

Os protótipos de abordagem construídos foram divididos em dois tipos: o Formal e o Lúdico. A base conceitual explorada nos dois protótipos foi a mesma, para que as distinções entre as Abordagens de Comunicação ficassem explícitas.

No protótipo Formal, construiu-se um roteiro mais próximo à realidade de mães, baseado em um jogo de tabuleiro. Para ganhar, o jogador deveria responder as questões corriqueiras relacionadas à saúde bucal do bebê, podendo em alguns momentos também receber dicas sobre a temática explorada. O jogo desafiava a mãe a chegar ao final do tabuleiro e resolver todos os desafios. Neste contexto, as mensagens foram direcionadas ao público adulto, usando termos técnicos em alguns momentos, além de serem formadas por orações e frases simples, porém com uma linguagem mais séria. Os discursos foram diretos e direcionados à usuária durante a interação. Completando este cenário, os ambientes e as telas do protótipo foram compostos por imagens rotineiras à mãe, como: crianças escovando os dentes e uma rotina familiar. $\mathrm{O}$ ambiente foi um elemento motivador e não era permitido à jogadora interagir com ele. Neste protótipo foram explorados conceitos relacionados a informações generalizadas sobre a saúde bucal do bebê. A interação com este protótipo ocorreu por meio do teclado, de forma simplificada. Na construção de uma narrativa interativa, foi levado em consideração o conceito de unicidade, ou seja, uma narrativa com início, meio e fim. Sendo assim, foi preciso que a narrativa reagisse ao jogador não só em determinados aspectos estéticos como também em determinado padrão que permitisse ao jogador entender, aprender e eventualmente dominar o jogo. Nas duas abordagens, atentou-se para que tal elemento estivesse presente. 
A abordagem Lúdica foi caracterizada pela presença de um roteiro e uma narrativa repletos de elementos divertidos, sem perder o embasamento teórico que subsidia os serious games. Neste protótipo o roteiro adotado foi o seguinte: em um reino muito distante havia um rei e uma rainha que acabaram de ter uma filha. O nascimento da criança foi amaldiçoado pelo bruxo Tártaro de modo que caso a princesa tenha algum problema dental todos do reino ficarão com os sorrisos tristes e os dentes podres. Para que isto não aconteça, a jogadora era estimulada a ajudar o rei e a rainha a evitar que tal maldição se concretize. Os discursos foram elaborados com base no enredo, por isso tinha como interlocutores dentes mágicos que conversaram com a mãe durante toda a interação. Durante a confecção do ambiente e das telas foi possível explorar elementos do imaginário, como dentes falantes, o bruxo e o encantamento. Após ser proposto o desafio no jogo, o público-alvo deveria iniciar uma busca aos dentes mágicos em um dos salões reais do castelo. Caso a mãe conseguisse resolver as situações-problemas expostas pelo jogo, receberia o título de heroína real. Os conteúdos explorados nesta abordagem foram os mesmos da Abordagem Formal, com a diferença presente na forma de apresentar tais informações aos jogadores.

Os protótipos relacionados às Abordagens de Comunicação foram testados na Clínica de Odontopediatria da UFPB. A clínica é frequentada por mães de baixa renda que buscam atendimento odontológico gratuito e de qualidade para seus filhos. A amostra avaliada se caracterizou por apresentar mães entre 25 e 35 anos de idade, sendo a maioria alfabetizada e com média de 2 a 3 filhos. Entretanto, era desconhecida a familiaridade deste público com a informática. Inicialmente, as mães interagiram com o protótipo relacionado à abordagem Lúdica e depois com a Formal. Após jogar os dois protótipos de teste, o formulário de avaliação foi aplicado sob a forma de entrevista e os dados foram registrados pelo entrevistador. Esta etapa de testes avaliou a opinião de 20 mães e ocorreu entre outubro de novembro do ano de 2010.

O tempo médio para jogar os dois protótipos e responder ao formulário foi de 35 minutos para cada mãe. Com vistas a otimizar o tempo durante as entrevistas, foi adotada uma estratégia para abordar as mães. Os passos adotados nesta estratégia foram:

- Apresentar as propostas da pesquisa e os objetivos da mesma no ambiente de espera da clínica, direcionado às mães que aguardavam atendimento;

- Convidar as mães para os testes de forma individualizada e apresentar os protótipos;

- Caso a mãe aceitasse o convite, o termo de consentimento livre e esclarecido era-lhe apresentado, esclarecendo a proposta de confidencialidade dos dados;

- A partir desse momento, a mãe interagia com os protótipos de abordagem de comunicação;

- $\quad$ O formulário era aplicado, os agradecimentos feitos e a pesquisa finalizada. 
De maneira geral, as mães tiveram facilidade ao jogar os protótipos de abordagem. A maioria teve receio quando recebia o notebook (em suas mãos), por medo de quebrar ou executar alguma ação que danificasse a máquina. Nesse momento, era exposto verbalmente que não era necessário tal temor, pois o entrevistador estaria ali para ajudá-las diante de qualquer dúvida. Os critérios de exclusão adotados nesta etapa da pesquisa foram: pais, mulheres que não são mães, mães analfabetas e crianças.

A faixa etária predominante no teste foi de mães acima de 38 anos, correspondendo a $60 \%$ das entrevistadas. Outra informação interessante é que $65 \%$ das mães disseram não ter conhecimento de informática. Contudo, tal limitação não afetou o desempenho e a motivação das mesmas durante os jogos. De maneira geral, as mães acharam interessante a ideia de fazer um jogo voltado para elas sobre esta temática. A importância de um serious game para a finalidade pretendida ficou clara ao se encontrar uma realidade em que mais de $80 \%$ das mães entrevistadas não haviam recebido nenhum tipo de orientação relacionada à higiene bucal do bebê. Neste grupo de mães, foram encontrados casos de algumas que levaram seus filhos para tratar cárie precoce na infância, decorrente de uma higiene bucal errada na fase de bebê. Informações equivocadas sobre higienização bucal foram comprovadas nesta amostra.

As distinções entre as abordagens foram notadas pelas mães ao longo das interações. Porém, as diferenças mais relevantes, segundo as mesmas, estavam nas narrativas. Tal fato pode ser comprovado pelo entendimento das mensagens nas duas abordagens. Os diários do entrevistador registraram que as mães ficavam mais atentas às questões na Abordagem Lúdica e elas normalmente tinham um desempenho melhor nessa abordagem, por causa do maior envolvimento causado pelo enredo e pelo roteiro.

Ao avaliar o elemento motivação nas duas abordagens, notou-se uma diferença percentual pequena entre as mesmas. Na abordagem Lúdica, as mães que declararam sentir algum tipo de motivação atingiram 90\% das entrevistadas, destas 35\% afirmavam estar muito motivadas, contrapondo $95 \%$ da abordagem Formal, com 30\% afirmando estarem muito motivadas. Porém, os diários do entrevistador relataram que as mães demonstravam maior vontade de terminar a Abordagem Lúdica, pois queriam "salvar a princesinha". Outro critério avaliado neste trabalho foi o critério nota atribuída pelas mães a cada uma das abordagens. As notas foram dadas dentro de uma escala de múltipla escolha, graduada de 1 a 5 . Ao final da etapa de testes, o protótipo lúdico conseguiu a nota média de 4.6 contrapondo os 4.4 obtidos pelo protótipo formal. Novamente, os resultados observados na aplicação da abordagem lúdica sugeriram um desempenho melhor do que a formal ${ }^{13,14}$.

\section{c) Desenvolvimento do Serious Game}

Uma vez concluída a fase de planejamento e após reuniões com a equipe multidisciplinar, o enredo adotado no jogo foi: "Era uma vez uma mãe que não cuidava da saúde bucal do seu filho 
recém-nascido. Vendo tamanho descuido a Fada do Dente resolveu testá-la, pois via que ela amava muito o seu bebê, mas não sabia que a sua higiene bucal era importante para o bem-estar e saúde do mesmo. Então, a Fada do Dente levou magicamente a mãe para uma floresta encantada, dominada pela Bruxa Banguela. Para retornar deste sonho a mãe (jogador) deve provar seus conhecimentos relacionados à saúde bucal dos bebês. Para isto, ela deve resolver os desafios, encontrar dicas e localizar as chaves para abrir o baú encantado, onde está o mapa para o esconderijo da Bruxa Banguela e a Escova Mágica para libertar bebês aprisionados pela mesma. Para chegar ao baú, a mãe precisará solucionar os desafios e acertar as questões bônus para receber partes da chave do baú. Os desafios propostos pela Fada envolverão temas relacionados à saúde bucal do bebê. Na Floresta da Dentolândia, a mãe encontrará seres encantados, chaves, dicas e desafios para chegar ao objeto encantado. A mãe só poderá chegar ao último desafio se acertar os anteriores e só poderá libertar os bebês se tiver força suficiente para vencer a Bruxa.”. Portanto, o jogo apresenta quatro personagens principais: a mãe (jogador), a Bruxa Banguela, a Fada do Dente e os coelhos encantados. A visão do jogo é em Primeira Pessoa e é por meio da personagem mãe que o jogador explora a Floresta da Dentolândia. A Fada do Dente ajuda ao público-alvo a quebrar o encanto existente nos bônus e os coelhos encantados contam as dicas. As ferramentas mágicas foram escondidas pela Bruxa Banguela e é ela quem apresenta os desafios para quebrar o feitiço das ferramentas.

A interação com o serious game ocorre por meio do mouse e do teclado, uma vez que o público alvo do jogo é um grupo bastante heterogêneo com relação aos conhecimentos de informática. Este serious game se enquadra na categoria de jogo de pistas, pois o jogador deve encontrar as ferramentas mágicas por meio das pistas recebidas a cada desafio correto. Este só ganha o jogo se pegar todas as ferramentas e obtiver pontos suficientes para destruir a Bruxa Banguela, salvando assim os bebês. O jogo possui três cenários principais: a floresta da Dentolândia, a casa da Bruxa Banguela e o esconderijo da Bruxa. Os dois últimos cenários só são liberados ao longo dos níveis. A floresta tem quatro regiões diferenciadas onde o jogador navega durante a maior parte da interação. O menu de navegação irá guiar o público-alvo para os próximos passos.

Nesta fase do desenvolvimento, o roteiro pedagógico estava delimitado. Porém, as questões relacionadas à saúde bucal do bebê precisavam ser definidas. Para isto, foi necessário delinear os tipos de questionamentos que apareceriam durante o jogo. Neste contexto, três grupos foram concebidos: os bônus, as dicas e os desafios. Cada um deles é requisitado em momentos específicos do serious game. Por exemplo: os bônus são ativados no momento em que o usuário tenta pegar as escovas encantadas; as dicas surgem quando o usuário interagir com os sorrisos mágicos; e os desafios são apresentados quando o usuário tiver todas as escovas mágicas e encontrar a ferramenta mágica do nível. Outra diferença relevante entre estes grupos é o objetivo de cada um deles. Enquanto os questionamentos existentes nas dicas exploram a dinâmica verdadeiro-falso nas respostas, as perguntas dos bônus e dos desafios utilizam respostas contextualizadas à rotina de cuidados com o bebê. Além disso, a diferença entre os bônus e os desafios é a complexidade das questões, pois os desafios contêm as assertivas de maior dificuldade. 
Uma vez esquematizada a lógica de manipulação da base de dados, sentiu-se a necessidade de elaborar um esboço do fluxo de dados do serious game "Uma Aventura na Floresta da Dentolândia". Esta atividade foi relevante no contexto do trabalho multidisciplinar, pois permitiu que a equipe opinasse sobre a dinâmica da ferramenta. $\mathrm{O}$ uso de diagramas para elucidar o fluxo do jogo foi importante para as próximas etapas do projeto, tais como: construção da árvore de decisão, escolha da metodologia de IA utilizada, dentre outras.

\section{d) Modelo de Decisão da Inteligência Artificial}

O processo decisório é uma ação executada naturalmente pelo homem. Esta capacidade é importante para o crescimento, aprendizado ou apenas para o curso da vida. As pessoas decidem baseadas em probabilidades constantemente calculadas e armazenadas em suas cabeças. O cérebro continuamente acumula porções de informação visual e auditiva conforme alguém observa uma cena, eventualmente juntando o suficiente para a pessoa tomar o que acredita ser uma decisão precisa $^{15}$. Incorporar o poder de decisão ao universo dos serious games possibilita o enriquecimento da prática pedagógica, permitindo a livre experimentação, o desafio, a exploração simultânea de vários sentidos e a motivação do processo de aprendizado.

A parceria entre o processo decisório e os serious games acontece por meio da Inteligência Artificial (IA). Ela é incorporada nos jogos com o intuito de lidar com as decisões do jogador e reagir automaticamente. Esta reação é dada pela inteligência artificial do jogo, que pode ser baseada em modelos de decisão.

A IA é geralmente incorporada aos projetos de jogos como um módulo separado que faz interface com o motor do jogo (game engine). Estes podem atuar de diversas maneiras e com objetivos variados, destacando-se: controle dos oponentes, avaliação dos processos decisórios do jogador, controle dos níveis de dificuldade, planejamento de ações, previsão das trajetórias de personagens e mudança de estados. Além destes, Bourg e Seeman ${ }^{16}$ também consideram os algoritmos de movimentação e colisão entre elementos como partes importantes da IA. A escolha do tipo de IA e da área de atuação da mesma no serious game é definida na etapa de planejamento. Neste contexto, diversas técnicas e metodologias são referenciadas na literatura, entre elas: máquinas de estado, redes neurais, redes bayesianas, lógica fuzzy, sistemas baseados em regras, algoritmos de busca e algoritmos genéticos. Neste trabalho, adotou-se o termo IA para se referir às tomadas de decisão da máquina. Millington ${ }^{17}$ afirma que nos serious games a IA pode atuar em níveis distintos, como: movimento, tomada de decisão e estratégia.

De posse do detalhamento do fluxo de jogo, foi possível estruturar e desenvolver os aspectos relacionados à IA do jogo. Neste processo, algumas etapas precisaram ser consideradas: a construção da árvore de decisão do jogo, o desenvolvimento de um grafo de eventos e, por fim, a escolha da metodologia de IA adotada. Definidas as temáticas centrais e o direcionamento do roteiro ao longo do jogo, foi possível descrever as ações e os eventos que ocorrerão de acordo 
com o processo decisório do público-alvo. Com estes dados, construiu-se a árvore de decisão ${ }^{18}$ do projeto (ilustrada na Figura 1). Este diagrama permite visualizar as consequências das decisões do jogador e os eventos aleatórios relacionados. As árvores de decisão se adequam a problemas facilmente representáveis pelo par atributo-valor. No entanto, outra abordagem a este problema foi a utilização de uma árvore pré-construída, que apenas é consultada no decorrer do jogo. Em projetos multidisciplinares, esta metodologia é bastante utilizada, pois permite que todos os componentes da equipe conversem sobre as consequências de uma decisão. Tal fato pode ser justificado pela clareza e simplicidade desses diagramas.

Outro diagrama importante para o jogo foi o grafo de evento. Ele foi construído para facilitar a análise relacionada à escolha da IA, apresentando de forma detalhada os eventos e suas transições de acordo com a dinâmica do jogo. Sua construção usou informações retiradas da árvore de decisão e do Game Bible do projeto. Cada evento apresentado neste diagrama deve apresentar apenas uma entrada e uma saída de acordo com sua definição.

O grafo de eventos no contexto do serious game "Uma Aventura na Floresta da Dentolândia", apresentado na Figura 2, mostra a sequência dos eventos de acordo com a apresentação dos bônus, dicas e desafios ao longo dos níveis. 
Figura 1: Árvore de decisão do serious game "Uma Aventura na Floresta da Dentolândia".

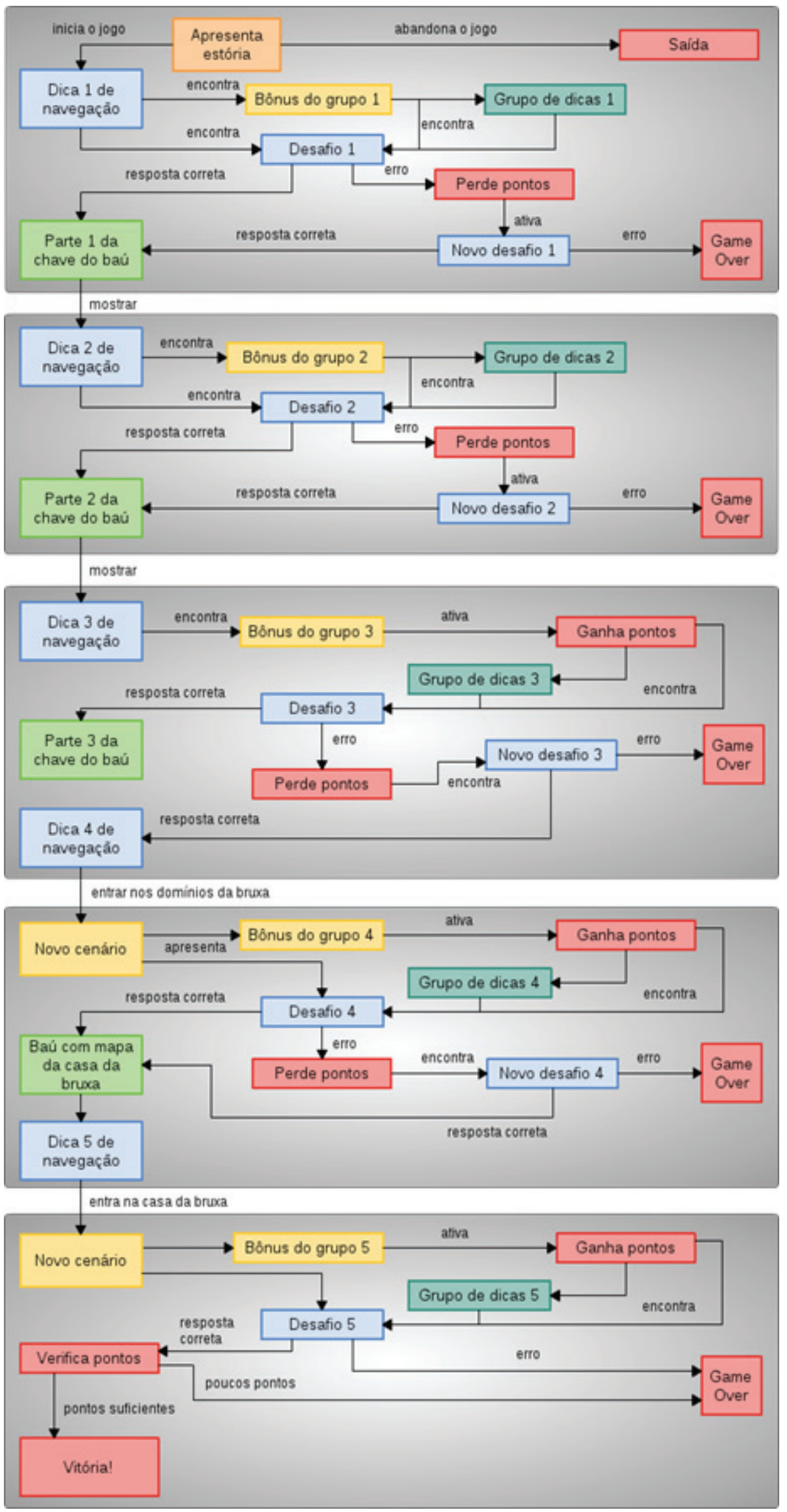


Ao se iniciar o jogo, o grafo mostra que o usuário deve solucionar todos os bônus existentes nas escovas encantadas para ativar o desafio do nível e com isso pegar a ferramenta mágica. Para isto, o jogador recebe dicas de navegação a fim de chegar até as escovas encantadas e as ferramentas. Contudo, ele ainda deve se preocupar em ativar os sorrisos mágicos existentes ao longo do ambiente, pois estes darão pontos extras de força em caso de acerto. Estes pontos são verificados no último nível para avaliar se o usuário detém conhecimentos suficientes para combater a Bruxa Banguela e salvar os bebês. Os sorrisos mágicos ganham dentes ao longo dos níveis e simulam a boca do bebê. Caso o usuário não ative os sorrisos e só pegue as escovas, o jogo ativa questões extras para avaliar o seu conhecimento.

De certa maneira, os grafos de eventos apresentam informações dadas pela árvore de decisão, porém de uma forma mais detalhada e sequencial. Este tipo de visualização foi importante durante a análise da natureza dos eventos que a IA do serious game deveria tratar.

Ao analisar o grafo de eventos e a árvore de decisão do jogo, percebeu-se que era possível mapear todos os estados e eventos tratados pela IA durante a interação com o jogador. Por isso, as metodologias de IA determinísticas foram consideradas para este projeto. Contudo, para entender melhor a dinâmica deste serious game, dividiram-se os estados entre três entidades distintas: as ferramentas, o jogador e os desafios. Para cada entidade foram modelados os estados e os eventos que ocasionavam a alteração entre eles. Após o mapeamento dos estados foi possível afirmar que o uso de Máquina de Estado era fundamental ao bom funcionamento do jogo. Após a análise dos tipos de máquinas e suas características, foi necessário chegar a algumas conclusões relacionadas à escolha da IA e suas possibilidades ${ }^{16}$. Inicialmente, os eventos foram definidos como finitos e determinísticos, por isso era possível trabalhar com quase todos os tipos de máquina de estados, exceto: as de estado Concorrente associadas a redes neurais e a redes bayesianas; as de estado Hierárquicas com a rede bayesiana; e as de estado Finitas, relacionadas às redes bayesianas.

Figura 2: Grafo de eventos do serious game "Uma Aventura na Floresta da Dentolândia".

Outra informação relevante refere-se ao tipo de variável do serious game desenvolvido. Neste caso, as variáveis de entrada do jogo não pertencem ao grupo das variáveis fuzzy, que lidam com valores incertos. Tal fato excluiu outro grupo de técnicas: Máquinas de Estados Difusos e as Fuzzy Hierárquicas, pois tais metodologias lidam com estados indeterminados ou incertos, característica da lógica difusa (também conhecida como lógica fuzzy). Por fim, a metodologia escolhida para este serious game foi o uso da Máquina de Estado Finita baseada na Lógica Clássica, pois este método lida com eventos finitos e determinísticos, além de se associar perfeitamente a Lógica Clássica. Outra vantagem é a baixa utilização de recursos do processador (CPU). Nos jogos computacionais esta preocupação é relevante, pois os processos gráficos consomem boa parte do processamento do hardware.

De todas as técnicas de IA usadas atualmente em jogos, as Máquinas de Estados Finitos são as 
mais utilizadas, não só por serem fáceis de compreender e programar, mas também pelo fato de serem aplicadas a quase todos os tipos de problemas ${ }^{16}$. Esta técnica pode ser utilizada juntamente com outras técnicas de IA existentes, tais como redes neurais ou Lógica Fuzzy, e permite separar cada comportamento possível de uma entidade em diferentes estados lógicos. A utilização das Máquinas de Estado Finitas em jogos, apesar de simples, consegue produzir resultados em que a inteligência é, pelo menos, aparente, ou seja, alcança um dos seus principais objetivos. A lógica Clássica na Computação está baseada na Lógica Booleana, trabalhando com a verificação de regras previamente estabelecidas pelo especialista e retornando verdadeiro ou falso. No caso dos jogos associados às Máquinas de Estados, esta lógica é incorporada nas regras para transição dos estados das entidades definidas. É uma técnica simples de implementar, mas requer um planejamento adequado dos estados e das regras do jogo.

Como citado anteriormente, as Máquinas de Estado Finitas podem se associar a outras técnicas de IA facilmente. Neste contexto, na fase de implementação da inteligência do serious game ocorreu a necessidade de controlar a seguinte situação: monitorar o desempenho da mãe ao longo das dicas. Para isto, optou-se usar os agentes inteligentes nesta tarefa. Lima ${ }^{19}$ define os agentes inteligentes como componentes que conseguem interagir com o ambiente a sua volta por meio de sensores e atuadores. Neste caso, os agentes ativarão dicas especiais no caso das mães possuírem pontuação baixa ou por não terem aberto nenhuma dica no nível.

\section{e) O Serious Game "Uma Aventura na Floresta da Dentolândia"}

O produto resultante do trabalho foi o jogo "Uma Aventura na Floresta da Dentolândia" (Figura 3). Esta aplicação é resultado das análises realizadas sobre os serious games na Odontologia e da aplicação prática de métodos de IA com intuitos informativos e educacionais. Observa-se que a construção do jogo foi baseada na Abordagem de Comunicação Lúdica e os principais elementos do jogo seguem suas características.

Após ser iniciado o jogo, o jogador entra na Floresta da Dentolândia. Para guiá-lo ao longo dos níveis e desafios há na parte inferior central da tela um menu de navegação que lhe indicará sempre os próximos passos que devem ser executados. Porém, há outros gráficos na tela que orientam o jogador durante a aventura, como pode ser observado na Figura 3. 
Figura 3: Cena do jogo "Uma Aventura na Floresta da Dentolândia".

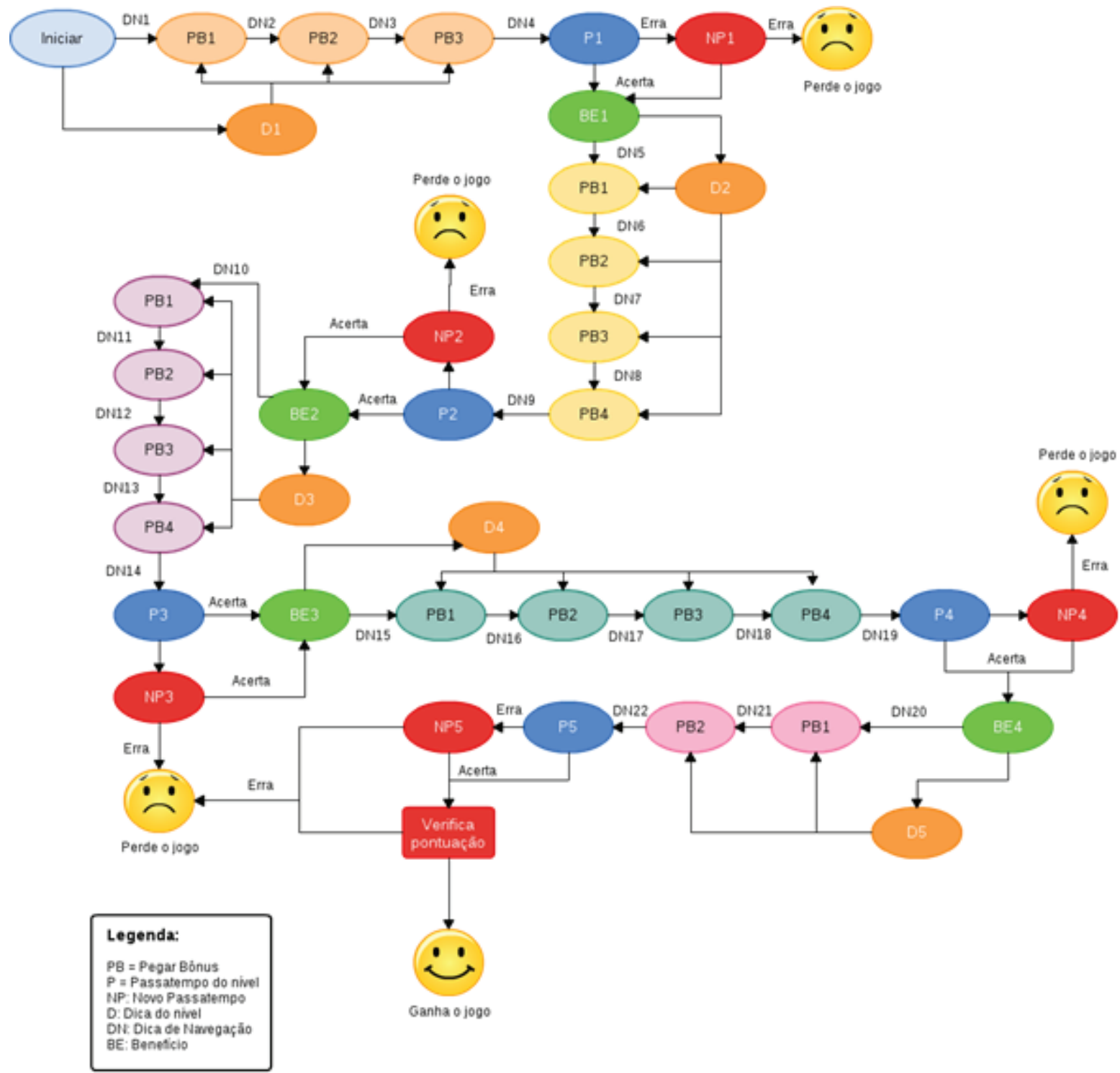

Para avaliar a opinião do público-alvo foi realizada uma pesquisa de opinião que teve como intuito observar as interações dos usuários com o jogo e colher impressões sobre diversos elementos da ferramenta. $\mathrm{O}$ formulário aplicado foi construído juntamente com a equipe multidisciplinar e aplicado na Clínica de Odontopediatria da Universidade Federal da Paraíba. A amostra foi voluntária. $\mathrm{O}$ formulário estava dividido nas seguintes partes: impressões sobre o jogo, relação com o dentista, conhecimentos gerais e perfil socioeconômico. Ao final, os testes foram realizados com uma amostra de 15 mães que acompanhavam seus filhos na clínica. O tempo médio de interação foi de 55 minutos por mãe. Após experimentarem o jogo, as mães respondiam as perguntas do formulário feitas pelo entrevistador.

No primeiro momento, o público-alvo opinou sobre suas impressões com relação ao serious game. De maneira geral, as mães gostaram do jogo, sendo que 100\% indicaram acreditar no fato destas aplicações ajudarem no aprendizado e, principalmente, na aquisição dos conceitos relacionados à 
saúde bucal do bebê. Ao final da interação, cerca de $87 \%$ das participantes entrevistadas obtiveram algum conhecimento novo que pretendem repassar para algum conhecido ou familiar. Dentro da amostra analisada, cerca de $53 \%$ das mães finalizaram o jogo com sucesso. Aquelas que não conseguiram finalizar o jogo indicaram a falta de tempo ou o término da consulta do seu filho na Clínica.

Posteriormente, foram analisadas as opiniões reportadas no formulário sobre três pontos: o jogo de maneira geral (conjunto começo-meio-fim), os desafios apresentados e as mensagens (de navegação e os discursos usados nos desafios). As opiniões foram positivas em todos estes aspectos. O público-alvo se sentiu muito motivado a interagir e concluir com sucesso a aplicação. Esta motivação ajuda no processo de imersão do jogador no enredo, além de melhorar os processos cognitivos do mesmo. Neste quesito, apenas uma das mães entrevistadas se sentiu pouco motivada com a aplicação. Durantes os testes, muitas mães manifestaram vontade de apresentar o jogo a outras familiares e sugeriram adicionar a possibilidade de navegar pela Floresta usando um personagem como avatar.

\section{CONCLUSÕES}

Durante o levantamento bibliográfico realizado para a presente pesquisa, foram encontrados diversos serious games relacionados à Odontologia. Estas aplicações possuem características bem definidas que podem ser comparadas ao serious game resultante deste trabalho. A primeira análise que deve ser destacada é o tipo de visualização deste jogo. Em meio a aplicações predominantemente 2D, o jogo "Uma Aventura na Floresta da Dentolândia" surgiu como uma ferramenta 3D específica para informar sobre conceitos relacionados à execução da higiene bucal a partir da fase de dentição decídua.

No trabalho desenvolvido podem ser destacados dois aspectos principais: a temática adotada (saúde bucal em bebês) e o público-alvo definido (cuidadores de bebês). Confrontando os dados do levantamento de aplicações, que mostra o predomínio dos temas relacionados à saúde e higienização bucal para um público-alvo generalizado, nota-se que este trabalho desenvolveu um serious game de temática inédita e relevante (considerando as bases de dados analisadas).

Concomitantemente, merece destaque a evolução do público-alvo dos jogos. Apesar das análises realizadas previamente neste trabalho, a etapa de teste final retomou um questionamento constante a todo processo de construção da ferramenta: a ampliação do público-alvo. Tal mudança é algo natural diante da crescente participação dos pais na educação e nos cuidados com os bebês. Esta realidade foi presenciada durante a etapa dos testes finais, onde um grande número de pais se apresentava na sala de espera da Clínica de Odontopediatria. Prevendo estas mudanças, o serious game "Uma Aventura na Floresta da Dentolândia" foi modificado para: evitar discursos diretos com a mãe nas mensagens ao longo do jogo e usar a visualização em primeira pessoa para evitar 
avatares femininos.

Outra característica particular deste serious games é o direcionamento das informações até o público foco. Normalmente nos serious games com intuitos educacionais o conteúdo é transmitido diretamente ao público-alvo da aplicação. Porém, quando se tem o foco em bebês há uma mudança neste fluxo de conceitos. Ou seja, a informação é transmitida a terceiros para afetar, de fato, o público central da aplicação.

Durante o planejamento e construção do serious game foi necessário garantir que o públicoalvo encontraria ao longo dos níveis todas as informações básicas da temática, independente dos caminhos percorridos pelo mesmo, mantendo sua motivação e interesse. Por isso, os processos decisórios do jogador foram analisados dentro de uma árvore de decisão a fim de definir a metodologia de IA mais adequada ao problema. Neste sentido, a IA implementada baseou-se em Máquinas de Estado Finitas associadas a Agentes Reativos, motivando, desafiando e auxiliando o percurso do jogador. É importante destacar que não há metodologia de IA padrão direcionada aos serious games relacionados à Odontologia e que a definição das técnicas deve ser realizada mediante estudos e análises do jogo a ser concebido. Dentro desta categoria de jogos, a transmissão de conceitos e informações deve ser considerada cuidadosamente para que nenhum aspecto seja esquecido.

Os resultados encontrados com a presente pesquisa permitiram verificar que as possibilidades temáticas são amplas para os serious games. Assim, assuntos como saúde bucal em bebês, higiene bucal em idosos, cuidados relacionados ao uso de aparelhos e peças ortodôndicas e cuidados bucais em gestantes são possibilidades reais de aplicação.

\section{REFERÊNCIAS BIBLIOGRÁFICAS}

1. Kebritchi M., Hirumi A. Examining the pedagogical foundations of modern educational computer games. Computers \& Education. 2008; 51(4): 1729-1743.

2. Moraes RM, Machado LS, Marques FLSN, Costa RMEM. Serious Games and Virtual Reality for Education, Training and Health. In: Maria Manuela Cruz-Cunha (Ed.). Handbook of Research on Serious Games as Educational, Business and Research Tools. IGI Global, 2012. p. 315-336.

3. Machado LS, Moraes RM, Nunes FLS, Costa RMM. Serious Games Baseados em Realidade Virtual para Educação Médica. Revista Brasileira de Educação Médica. 2011; 35(2): 254-262.

4. ABRAGAMES. I Censo da Indústria Brasileira de Jogos Digitais. 57p. Disponível em: 
$<$ http://www.abragames.org/files/downloads/829630556e3acdd35ff.pdf $>$. Acesso em jul/2015.

5. Almeida TF et al. Family context and incidence of dental caries in preschool children living in areas covered by the Family Health Strategy in Salvador, Bahia State, Brazil. Cadernos de Saúde Pública. 2012; 28(6): 1183-1195.

6. Brasil. Ministério da Saúde. Secretaria de Atenção à Saúde. Secretaria de Vigilância em Saúde. SB Brasil 2010: Pesquisa Nacional de Saúde Bucal: resultados principais / Ministério da Saúde. Secretaria de Atenção à Saúde. Secretaria de Vigilância em Saúde. Brasília: Ministério da Saúde, 2012. 116 p.

7. Silveira ER et al. Maternal attitudes towards tooth decay in children aged 12-18 months in Pelotas, Brazil. European Archives of Paediatric Dentistry. 2015; 16(5):383-389.

8. Bueno RE. Protocolo de atenção à saúde bucal por ciclos de vida. Revista Gestão \&Saúde. 2010; 1(20): 18-26.

9. Ito C. Uma Alternativa de Conscientização Sobre Prevenção Odontológica: Desenvolvimento e Avaliação do protótipo de um Serious Game [Dissertação]. [São PauloBrasil]: Centro Estadual de Educação Tecnológica Paula Souza; 2011. 93 p.

10. Kolesnikov M., Zefran M, Steinberg A, Bashook P. PerioSim: Haptic Virtual Reality Simulator for Sensoriomotor Skill Acquisition in Dentistry. IEEE International Conference on Robotics and Automation (ICRA’09); 2009 May 12-17; Kobe, Japan. p. 689-694.

11. Rodrigues H, Machado, Valença A. Applying Haptic Systems in Serious Games: A Game for Adult's Oral Hygiene Education. SBC J. on Interactive Systems. 2014; 5(1): 16-25.

12. Schell J. A Arte de Game Design: o livro original. Rio de Janeiro: Campus. 2011.

13. Morais AM, Rodrigues HF, Machado LS, Valença AMG. Planning Serious games: Adapting Approches for Development. Lecture Notes in Computer Science. 2010; 6249: 385-394.

14. Morais AM, Machado LS, Valença AMG. Definindo a Abordagem de Comunicação no Planejamento de um Serious games Voltado para Saúde Bucal em Bebês. XXX Congresso da Sociedade Brasileira de Computação - X Workshop de Informática Médica, 2010 Jul 20-23; Belo Horizonte/MG, Brazil. p. 1556- 1565.

15. Green CS, Pouget A, Bavelier D. Improved Probabilistic Inference as a General Learning 
$186 / /$

Mechanism with Action Video Games. Current Biology. 2010; 20(17): 1573-1579.

16. Bourg DM, Seeman G. AI for Game Developers. O’Reilly. 2004.

17. Millington I, Funge J. Artificial Intelligence For Games. CRC Press. 2a edição, 2009.

18. Leite Jr AJM, Severo APA. A Importância da Imagem no Processo de Imersão do Usuário em Jogos Eletrônicos. VII Simpósio Brasileiro de Jogos e Entretenimento Digital (SBGAMES); 2008 Nov. 10-12; Belo Horizonte/MG, Brasil. 10p. Disponível em: http://www.sbgames.org/papers/ sbgames08/artanddesign/full/ad1_08.pdf.

19. Lima I, Pinheiro C, Santos F. Inteligência Artificial. Rio de Janeiro: Elsevier, 2014.

Artigo apresentado em 11/06/15 Artigo aprovado em 18/03/16 Artigo publicado no sistema em 31/03/16 
DOI:

\title{
Modelagem do Comportamento Hemodinâmico de um Paciente Virtual Cirúrgico baseado em Sistema Especialista Fuzzy.
}

\author{
Hemodynamic behavior modeling of a Virtual Surgical \\ Patient based on a Fuzzy Expert System.
}

\section{Modelado de comportamiento hemodinámico de un paciente quirúrgico virtual basado en un Sistema Esperto Fuzzy.}

Paulo V. F. Paiva ${ }^{1}$

Liliane S. Machado ${ }^{2}$

Tâmela Costa ${ }^{3}$

RESUMO: A Realidade Virtual (RV) permite aos seus usuários experimentarem uma sensação de estarem imersos em cenários 3D sintéticos gerados por computação gráfica. Os chamados Ambientes Virtuais (AVs) de RV, quando aplicados à educação médica, possibilitam: treino repetitivo e o desenvolvimento de habilidades psicomotoras em procedimentos cirúrgicos sem o comprometimento de pacientes reais. Os simuladores cirúrgicos que apresentam Pacientes Virtuais (PVs), isto é, que apresentam sensibilidade fisiológica às intervenções e decisões médicas tomadas ao longo do treinamento, são mais requisitados pela possibilidade de variação de casos clínicos gerados, aumentando portanto o grau de realismo. Este trabalho tem por objetivo principal, discutir importantes aspectos sobre a modelagem do comportamento hemodinâmico de um PV cirúrgico, especificamente das variáveis de Pressão Arterial Sistólica (PAS) e Diastólica (PAD) em momentos distintos da indução anestésica. Como resultado tem-se a proposição de um modelo de PV e de uma arquitetura de integração deste a sistemas de simulação baseados em RV.

Palavras-chave: Simulação de Paciente, Simulação por Computador, Lógica Fuzzy, Anestesiologia.

\footnotetext{
ABSTRACT: The Virtual Reality (VR) allows its users to experience a sense of being immersed in synthetic 3D scenarios generated by computer graphics. The so-called Virtual Environments 1 Laboratório de Tecnologias para o Ensino Virtual e Estatística (LabTEVE). Universidade Federal da Paraíba. Campus I. Jardim Cidade Universitária. João Pessoa - PB. E-mail: paulo.fariaspaiva@gmail.com

2 Docente do Departamento de Informática e pesquisadora junto ao Laboratório de Tecnologias para o Ensino Virtual e Estatística (LabTEVE). Universidade Federal da Paraíba. Campus I. Jardim Cidade Universitária. João Pessoa - PB. E-mail: liliane@di.ufpb.br

3 Laboratório de Tecnologias para o Ensino Virtual e Estatística (LabTEVE). Universidade Federal da Paraíba. Campus I. Jardim Cidade Universitária. João Pessoa - PB. E-mail: tamela_costa@hotmail.com
} 
(VEs) based on RV can be applied to medical education, enabling: repetitive training and the development of psychomotor skills in surgical procedures without compromising real patients. Surgical simulators that feature Dynamic Virtual Patients (VPs), that is, reacts physiologically to interventions and medical decisions made during the training. These systems present more realism while it offers the possibility of varying clinical cases. This work has as main objective to discuss important issues of modeling the hemodynamic performance of a VP, specifically to simulate blood pressure values (both sistolic and diastolic variables). The model of a VP is presented as result as well as is presented an architecture for its integration to simulators based on VR.

Key-words: Patient Simulation, Computer Simulation, Fuzzy Logic, Anesthesiology.

RESUMEN: La Realidad Virtual (RV) permite a sus usuarios experimentar una sensación de estar inmersos en escenarios 3D sintéticos generados por los gráficos de computadora. Los llamados entornos virtuales (AVs) de RV cuando se aplican a la educación médica, permiten: entrenamiento repetitivo y el desarrollo de habilidades psicomotrices en procedimientos quirúrgicos sin comprometer pacientes reales. Simuladores quirúrgicos que cuentan con pacientes virtuales (PV) dinámicos, es decir, que tienen la sensibilidad fisiológica de las intervenciones y las decisiones médicas tomadas durante el entrenamiento, que son los más buscados por la posibilidad de variar los casos clínicos generados, lo que aumenta el grado de realismo. Este trabajo tiene como objetivo principal discutir aspectos importantes de modelar el comportamiento hemodinámico de un PV, específicamente las variables de la presión arterial sistólica (PAS) y diastólica (PAD). Como resultado se presenta la propuesta de un modelo PV y una arquitectura de integración de este modelo en sistemas de simulación basados en RV.

Palavras clave: Simulación de Paciente, Simulación por Computador, Lógica Fuzzy, Anestesiología.

\section{INTRODUÇÃO}

A tecnologia da Realidade Virtual (RV) é um ramo inter e multidisciplinar do conhecimento humano e que permite a simulação de eventos diversos em ambientes gráficos tridimensionais, sendo estes denominados Ambientes Virtuais (AVs) ${ }^{1}$. Algumas das principais características dos AVs são: respostas às ações do usuário em tempo real (interatividade); aguçamento da cognição dos usuários fazendo-os sentirem-se imersos em uma realidade alternativa (princípio de imersão); uso de dispositivos eletrônicos para interação homem-máquina não convencionais (ex: luvas de dados, dispositivos que exploram o tato), dentre outras ${ }^{2}$. No contexto da educação em saúde, a medicina certamente é uma das áreas mais beneficiadas com o advento desta tecnologia. Os simuladores baseados em RV voltados para a medicina (ou simuladores médicos), possibilitam a redução de custo na formação de novos médicos, o uso de técnicas de ensino mais interativa, e diminuição de uso de cobaias animais e cadáveres, favorecendo os aspectos éticos envolvidos na formação de novos profissionais ${ }^{2,3}$.

A princípio, uma simulação gráfica constitui-se de um modelo matemático e físico de um ou 